\title{
Specification a Model for Study of Social Tandem
}

\author{
Cruz García Lirios* \\ Autonomous University of the State of Mexico, Mexico
}

*Corresponding author: Cruz García Lirios, Autonomous University of the State of Mexico, Mexico

\begin{abstract}
Social representations are visions of the everyday world that is historically constructed alongside the dissemination of media intensifies their audiences. In this sense, the printed media availability and water policy has not only been systematically reduced to opinions by the press, but also two logics have been grown on the credibility of the information and the verifiability of it. In this sense, this study exposes the lines of discussion for the analysis of tandem policies and agenda setting in the availability and supply of water. The results show frames from newspaper audiences are considered promoters of a relative deprivation that is the conformism of the service quality of public water supplies.
\end{abstract}

Keywords: Compliance; performance; availability; supply rate

\section{Introduction}

The relationship between authorities and users of public services has been a central issue on the agenda of the media. In the case of water as a strategic resource for local development, quality of life and subjective well-being, in recent years it has been widely reported by the media [1].

Particularly the print media with national circulation has included reports about the imbalance posed by water scarcity and water shortages associated with the corruption of local authorities and increased rates deregulated [2].

The impact of media coverage regarding the shortage and poor health has been a central issue in the public health agenda [3]. It is estimated that about six million children die from diseases hydrotransitions in countries with high rate of water shortages, but this means not only disseminate information but also associate the performance of the authorities in terms of management.

Thus, in the suburbs of large cities the problem of water supply has been addressed by a system of tandem in which increasingly restricted water consumption and substantially increase rates [4].

Approximately $20 \%$ of incomes in vulnerable or water exclusion situation, is assigned to the purchase of water products, but print media rather highlight the lack of infrastructure and attention to contingencies such as drought or frost [5].

Thus, the media have a view of the problem of water scarcity and shortages of attributing responsibility to the authorities and exonerating users who have regular access to drinking water or justifying the soft drink consumption or pharmaceutical industry.

It is a process in which the systematic dissemination of biased information regarding the relationship between availability and management of water resources is known as agenda setting [6].

An agenda is a result of information exchange between the agents involved, but the differences between them generates information biases that are spread in the media and the information is used to justify rate increases by the authorities, waste by users, conflicts among actors or, tandem or policies restricting water [7].

However, the agenda is also historic, as it involves the reaction of organized civil society groups regarding the performance of its authorities on quality public services [8].

It is power relations that have grown and are activities to the less informative provocation, but in the case of the print media is a process more complex elaboration that this letter sets as an overview of water availability in reference to consumption human.

If the media presented the conflict as central themes of water problems because the authorities responsible for the inefficiency of rates and expose closures avenues, boycotts pipe facilities or kidnappings as evidence of ungovernability that inhibit local sustainable development.

Consider the following premises for addressing administrative corruption on supply and collection of public drinking water: 
A. Premise 1: The availability of resources to be scarce generates an administration of austerity and shortages financed by a steady increase in the unit price of water in terms of political relations between local governments and civil society organizations.

B. Premise 2: The rates reflect political negotiations between members and militants about election time and the proximity of local elections, but also in terms of management capabilities of civil society organizations.

C. Premise 3: Conflicts between civil society and local government in the field of municipal water services are a reflection of systematic dissemination of shortage and quality of drinking water in the media with particular emphasis on national newspapers.

D. Formulation: What is the proposed media for the sustainability of supply and collection system considering his framing of the facts?

E. Hypothesis: The journalistic framing printed media around scarcity, and water management is established from the systematic diffusion of responsibility of local officials.

\section{Methods}

A. Design: Non-experimental, retrospective, documentary and exploratory study.

B. Sample: Notes the daily newspaper of national circulation during the period from 2010-2015

C. Instrument: Matrix analysis of content including references consulted and processed information as shown, instruments and results (see table 1 in annex).

D. Procedure: Estimated impact of press releases considering its content and frequency of keywords or indicators of scarcity, shortage and cost of drinking water.

\section{Results}

The weights of notes and images as well as their mutual correspondence concerning the coverage of water leaks Iztapalapa. The indices show that the items appear to be biased as they reached a total value of 4 points of 44 possible. Only in notes III (Alistan constitution water Iztapalapa) and V (is lost in leaks 35\% water) reporters tried to externalize their opinion on the issue. The note V journalist quotes two officers: David Robles and Hector Reyes to support the header of your report regarding the volume is wasted by visible and invisible leaks without establishing a percentage distinction between the two issues and link it with 35\% announcing at the top of the note [9].

Regarding framed pictures, media coverage seems to be high since it reached a total of 36 points of 44 possible. A quarter of the selected notes reached the maximum weighting relative to framing. IX and X notes included images out of context without any connection with the note. Such notes did not try to influence or confuse readers.

However, the notes I, II, III, IV, V, VI, VII, VIII and XI included images that seems evident extreme shortages; public service users storing water in drums, jars and buckets. Or, images where principal photography leaks seem to be uncontrollable.

In the case of the relationship between discourses and images, the index was 22 Framed Hybrid which was considered moderate as only the notes III, VI, IX and X included images that did not correspond to the briefing notes.

However, if the note III who headed: "ready incorporation of water in Iztapalapa" included images of water users away. That is, "El Universal" describes a leak to argue the need for a legal agreement and illustrates his message with images relating to a possible consequence: the improvised water storage.

Finally, the index Mediatization Leak scored a total of 62 of 132 possible to settle at a moderate level. That is, the press coverage about the shortage prompted by leaks seem to have an unusual bias in relation to the description and illustration of the water situation is diffused.

\section{Discussion and Conclusion}

The results showed a moderate mediation except Framed Images Index (IEI), which was close to a very high degree of media coverage. Such findings are consistent with those found by GarciaLilies [8] who found moderate levels of media coverage regarding the participation of users in situations of scarcity and shortage.

\section{References}

1. Anaya Genaro (2014) Anthropocentric: A mistaken concept Entretextos. 6(7): 1-12.

2. Gomera Antonio, Villamandos Francisco, Vaquero Manuel (2013) Construction of indicators of environmental beliefs from the NEP scale. Psychological Action 10(1): 149-160.

3. McCombs M (1996) Influence of news about our images of our world. In J Bryant, Zillman D (eds.). The effects of the media. research and theories. Polity Press, Barcelona, Spain pp. 13-34.

4. Gudynas Eduardo (2010) Biocentric path: Intrinsic values of nature rights and ecological justice Tabula Rasa. 13: 45-71.

5. Perez David, y Soler Martha (2013) Agroeconomics and ecofeminism to decolonize and depatriarchalize global power. International Journal of Political Thought 8 (1): 93-103.

6. Carreon Javier, Hernandez Jorge, Garcia Cruz, Bustos Jose, Morales Maria, et al. (2014) The Psychology of water sustainability. Public policies and consumption patterns. Aposta 63: 1-29.

7. Flores Raul (2013) Research of social representations of the environment in Brazil and Mexico. Rev Actual Investig Educ 13 (1): 292-312.

8. Garcia Lilies C (2011) Water mediation of participation in Iztapalapa. In Pihedraita J (eds). Social management for human development, UCMC: Bogota, USA, pp. 521-547.

9. Soto Giovannie (2012) Sustainable development or environmental ethics. Articles and Essays of Rural Sociology 7(13): 7-19. 
CC (P) This work is licensed under Creative

To Submit Your Article Click Here: Submit Article

DOI: 10.32474/JAAS.2020.01.000114

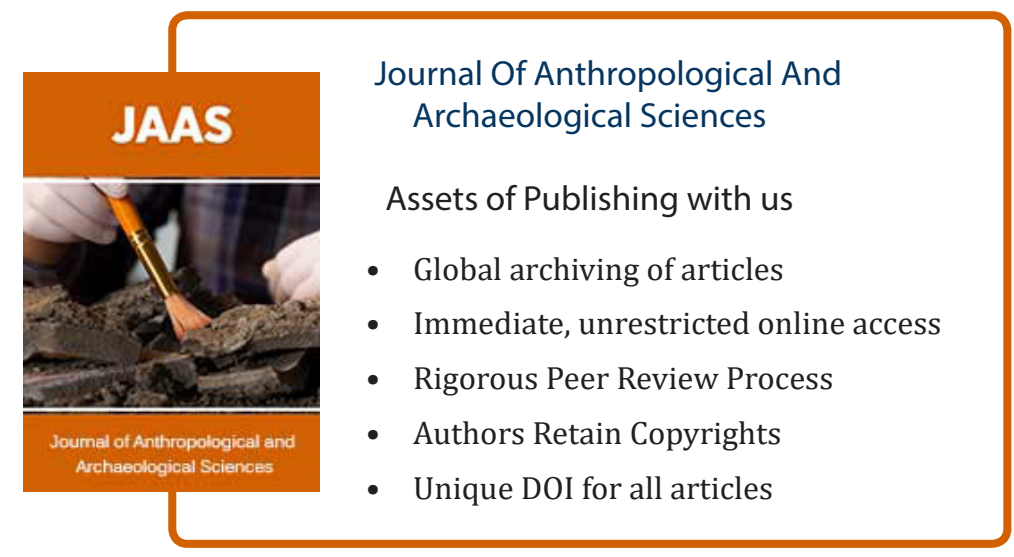

